\title{
The first patient reported with X-linked severe combined immunodeficiency in Peru
}

\section{Juan Carlos Aldave ( $\nabla$ jucapul_84@hotmail.com )}

Hospital Nacional Edgardo Rebagliati Martins https://orcid.org/0000-0003-3548-0385

\section{Enrique Cachay}

Hospital Nacional Edgardo Rebagliati Martins

\section{Guisela Alva}

Hospital Nacional Edgardo Rebagliati Martins

\section{Mariela Milla}

Hospital Nacional Edgardo Rebagliati Martins

Joel Calero

Hospital Nacional Edgardo Rebagliati Martins

\section{Case report}

Keywords: X-linked severe combined immunodeficiency, X-SCID, Hematopoietic Stem Cell Transplantation, Gene therapy, Primary immunodeficiency

Posted Date: July 27th, 2020

DOI: https://doi.org/10.21203/rs.3.rs-47002/v1

License: (c) (i) This work is licensed under a Creative Commons Attribution 4.0 International License. Read Full License 
5

6

7

8

9

10

11

12

13

14

15

16

17

\section{The first patient reported with $\mathrm{X}$-linked severe combined immunodeficiency in Peru}

Juan Carlos Aldave ${ }^{1 *}$, Enrique Cachay ${ }^{1}$, Guisela Alva ${ }^{1}$, Mariela Milla ${ }^{1}$, Joel Calero ${ }^{1}$

Affiliations:

1. Allergy and Immunology Division, Hospital Nacional Edgardo Rebagliati Martins, Lima, Peru

Correspondence to:

Juan Carlos Aldave, MD

E-mail: jucapul_84@hotmail.com

Address: Jr. Domingo Cueto 369, dpto. 301, Lince, LIMA 14, Peru

Phone: (+51) 988-689-472

Number of words: 836

Number of figures: 0 


\author{
18 ABSTRACT \\ 19 \\ 20

\section{Background} \\ $\mathrm{X}$-linked severe combined immunodeficiency (X-SCID) is a life-threatening immune \\ disorder caused by pathogenic mutations in the $I L 2 R G$ gene. We report the first patient with \\ genetically confirmed X-SCID in Peru.

\section{Case presentation} \\ Diagnosis was suspected before patient's birth because of family history. At birth, blood \\ immunophenotype was compatible with X-SCID and genetic analysis revealed a pathogenic \\ mutation in $I L 2 R G$. Intravenous immunoglobulin and antibiotic prophylaxis were initiated \\ until patient's referral for an available novel treatment: gene therapy.

\section{Conclusions} \\ 32 Family background is a key point to suspect X-SCID, allowing a timely diagnosis and \\ 33 treatment. X-SCID requires prompt immune reconstitution. However, HSCT is frequently not \\ 34 available to treat newborns in developing countries.

\section{Keywords} \\ X-linked severe combined immunodeficiency, X-SCID, Hematopoietic Stem Cell




\section{BACKGROUND}

$\mathrm{X}$-linked severe combined immunodeficiency (X-SCID) is a potentially fatal primary immunodeficiency characterized by profound impairment of both cellular and humoral immunity, leading to an increased susceptibility to serious infections by many kinds of microbes including opportunistic [1].

We report the first patient with genetically confirmed X-SCID in Peru.

\section{CASE PRESENTATION}

A 33-week-pregnant woman carrying a male fetus was referred for an immunological evaluation because her previous two male children had deceased at early age due to severe infections. She also had an apparently healthy 8 -year-old daughter.

The first deceased boy was born at 36 weeks of gestation. At 6 months of age he presented with failure to thrive and pneumonia requiring management at intensive care unit. However, he evolved with chronic diarrhea, dying at 8 months of age due to intestinal perforation, peritonitis and sepsis.

The second deceased boy was born at 32 weeks of gestation. At 5 months of age he presented with chronic diarrhea, failure to thrive and Pneumocystis jirovecii pneumonia. Laboratory work up showed hypogammaglobulinemia and absence of $\mathrm{T}$ cells. Despite therapy with intravenous immunoglobulin, the boy died at 11 months of age due to systemic infection by Mycobacterium tuberculosis and cytomegalovirus.

On account of the family history, we suspected a diagnosis of X-SCID in the coming male baby, with a disease probability of $50 \%$. Therefore, we decided to manage him as potentially sick with the following recommendations: programmed Cesarean delivery, strict isolation, breastfeeding avoidance, Bacille Calmette-Guérin (BCG) vaccine avoidance, immediate immunologic testing to confirm the diagnosis, and urgent hematopoietic stem cell transplantation (HSCT) if the diagnosis was confirmed.

Six weeks later, the patient was born through programmed Cesarean delivery, with a gestational age of 39 weeks and a birth weight of $3500 \mathrm{~g}$. Although the patient looked apparently healthy, immediate immunologic testing was performed. Total leukocyte $(16,490 / \mu \mathrm{L})$, lymphocyte $(2,800 / \mu \mathrm{L})$ and neutrophil $(10,550 / \mu \mathrm{L})$ counts were within normal values, the same as hemoglobin $(19.5 \mathrm{~g} / \mathrm{dL})$, platelets $(313,000 / \mu \mathrm{L})$ and serum immunoglobulins. However, flow cytometric analysis revealed a virtual lack of $\mathrm{T}$ cells and NK cells, with a normal B-cell count ( $97 \%$ of lymphocytes).

The presence of a T-B+NK- immunophenotype was highly suggestive of X-SCID. Therefore, we proceeded to sent blood samples to Children's Hospital Boston, USA for genetic testing, which confirmed the disease-causing mutation c.270-15a>g in the interleukin 2 receptor subunit gamma (IL2RG) gene. In the meantime, the patient was in strict isolation while receiving prophylaxis with intravenous immunoglobulin, cotrimoxazole and itraconazole. BCG was not administered and breastfeeding was avoided. 
The patient required an urgent potentially-curative therapy with HSCT. Nevertheless, there are several limitations to perform HSCT in Peru, such as the lack of a bone marrow national registry to look for human leukocyte antigen (HLA)-matched unrelated donors, and a lack of well-trained transplantation teams for primary immunodeficiencies. Our reported patient did not have an HLA-matched related donor, so he was referred to the United States of America for a novel treatment: gene therapy.

\section{DISCUSSION AND CONCLUSIONS}

$\mathrm{X}$-SCID is a life-threatening primary immunodeficiency characterized by profound impairment of both cellular and humoral immunity [1]. Pathogenic mutations in the IL2RG gene lead to absent production or abnormal function of the common gamma chain protein, also called CD132 [2,3]. Defects in this protein result in a virtual absence of $\mathrm{T}$ and $\mathrm{NK}$ lymphocytes, with a normal B-lymphocyte count (T-B+NK- immunophenotype) [4]. Immunoglobulin production is impaired despite the presence of normal B-cell numbers. This is explained by the lack of $\mathrm{T}$ cell collaboration for antibody production and the presence of abnormal growth factor receptors on B cell surface [5].

X-SCID patients typically present in the newborn period with chronic diarrhea, failure to thrive and severe, recurrent infections by any kind of microbe including opportunistic ones. Some patients have an atypical milder presentation [7-9]. Asymptomatic children with abnormal newborn screening for SCID or family history of X-SCID should be fully evaluated.

Regarding our case, patient's family history allowed us to suspect X-SCID and to establish an appropriate management since birth. Our patient had a classical immunophenotype of XSCID. As we expected, a pathogenic mutation was found in the IL2RG gene.

Primary treatment for X-SCID is HSCT [10,11]. The best timing for this procedure is immediately after birth. It has been established that better outcomes ( $>90 \%$ survival) are achieved in patients who receive transplantation in early infancy, below 3.5 months of age [10]. Provisional management includes immunoglobulin administration and antibiotic prophylaxis against Pneumocystis jirovecii and fungal infections [12]. The role of gene therapy is being investigated; there is evidence of effectiveness, but potential of oncogenic insertions should be considered [13].

We report the first patient with genetically confirmed X-SCID in Peru. Diagnosis was suspected before birth because of his family history. Early diagnosis allowed an adequate management until his referral to a gene therapy protocol.

Family background is a key point to suspect X-SCID, allowing a timely diagnosis and treatment. This severe life-threatening disease requires prompt immune reconstitution. However, HSCT is frequently not available to treat newborns in developing countries due to medical and administrative limitations. What should we do if SCID is confirmed in these newborns? Are they condemned to die?

\section{List of abbreviations}


X-SCID: $\quad$ X-linked severe combined immunodeficiency

BCG: $\quad$ Bacille Calmette-Guérin

HSCT:

Hematopoietic stem cell transplantation

HLA:

Human leukocyte antigen

143 IL2RG:

Interleukin 2 receptor subunit gamma

144 SCID:

Severe combined immunodeficiency

\section{DECLARATIONS}

\section{Ethics approval and consent to participate}

No approval was needed from the ethics committee.

\section{Consent for publication}

Parents of the patient gave consent to publish the current manuscript.

\section{Availability of data and materials}

Data from the patient is available in his physical clinical history at Edgardo Rebagliati Martins National Hospital (Lima, Peru).

\section{Competing interests}

The authors declare that they have no competing interests.

\section{Funding}

The elaboration of the current manuscript was self-funded.

\section{Author's contributions}

All authors contributed to the evaluation, diagnosis, and management of the patient. JCA and JC were major contributors in writing the manuscript. All authors read and approved the final manuscript.

\section{Acknowledgements}

We thank God for His peace and wisdom. We thank the patient and his family for the invaluable lessons of life they gave us. We acknowledge the members of our clinical and laboratory team for their excellent work. We are grateful with Dr. Luigi Notarangelo and team for their huge support with gene sequencing.

\section{REFERENCES}

1. Baker MW, Grossman WJ, Laessig RH, Hoffman GL, Brokopp CD, Kurtycz DF, et al. Development of a routine newborn screening protocol for severe combined immunodeficiency. J Allergy Clin Immunol 2009; 124(3):522-7.

2. Noguchi M, Yi H, Rosenblatt HM, et al. Interleukin-2 receptor gamma chain mutation results in X-linked severe combined immunodeficiency in humans. Cell 1993; 73:147.

3. Schmalstieg FC, Goldman AS. Immune consequences of mutations in the human common gamma-chain gene. Mol Genet Metab 2002; 76(3):163.

4. Noguchi M, Yi H, Rosenblatt HM, Filipovich AH, Adelstein S, Modi WS, et al. Interleukin-2 receptor gamma chain mutation results in X-linked severe combined immunodeficiency in humans. Cell 73: 147- 157. 1993. J Immunol 2008; 181(9):5817-27. 
5. Kalman L, Lindegren ML, Kobrynski L, Vogt R, Hannon H, et al. Mutations in genes required for Tcell development: IL7R, CD45, IL2RG, JAK3, RAG1, RAG2, ARTEMIS, and ADA and severe combined immunodeficiency: HuGE review. Genet Med 2004; 6(1):16-26.

6. Conley ME. Molecular approaches to analysis of X-linked immunodeficiencies. Ann Rev Immunol. 1992;10:215-238.

7. Wada T, Yasui M, Toma T, et al. Detection of T lymphocytes with a second-site mutation in skin lesions of atypical X-linked severe combined immunodeficiency mimicking Omenn syndrome. Blood 2008; 112:1872.

8. Slatter MA, Angus B, Windebank K, et al. Polymorphous lymphoproliferative disorder with Hodgkin-like features in common $\gamma$-chain-deficient severe combined immunodeficiency. J Allergy Clin Immunol 2011; 127:533.

9. Conley ME. Molecular approaches to analysis of X-linked immunodeficiencies. Ann Rev Immunol. 1992;10:215-238.

10. Filipovich A. Hematopoietic cell transplantation for correction of primary immunodeficiencies. Bone Marrow Transplant 2008; 42 Suppl 1:S49.

11. Myers LA, Patel DD, Puck JM, Buckley RH. Hematopoietic stem cell transplantation for severe combined immunodeficiency in the neonatal period leads to superior thymic output and improved survival. Blood. 2002;99:872-8.

12. Allenspach E, Rawlings DJ, Scharenberg AM. X-Linked Severe Combined Immunodeficiency. 2003 Aug 26 [Updated 2016 Apr 14]. In: Pagon RA, Adam MP, Ardinger HH, et al., editors. GeneReviews ${ }^{\circledR}$ [Internet]. Seattle (WA): University of Washington, Seattle; https://www.ncbi.nlm.nih.gov/books/NBK1410/ 1993-2017. Available from: 13. Fischer A, Hacein-Bey-Abina S, Cavazzana-Calvo M. Gene therapy for primary immunodeficiencies. Immunol Allergy Clin North Am 2010; 30:237. 